\title{
Clinical outcomes and management of mechanism-based inhibition of cytochrome P450 3A4
}

\author{
Shufeng Zhou' \\ Eli Chan' \\ Xiaotian $\mathrm{Li}^{2}$ \\ Min Huang ${ }^{3}$ \\ 'Department of Pharmacy, Faculty of \\ Science, National University of \\ Singapore, Singapore; ${ }^{2}$ Department of \\ Maternal and Fetal Medicine, \\ Obstetrics and Gynecology Hospital, \\ Fudan University, Shanghai, China; \\ ${ }^{3}$ Department of Clinical \\ Pharmacology, School of \\ Pharmaceutical Science, Zhongshan \\ University, Guangzhou, China
}

\begin{abstract}
Mechanism-based inhibition of cytochrome P450 (CYP) 3A4 is characterized by $\mathrm{NADPH}$-, time-, and concentration-dependent enzyme inactivation, occurring when some drugs are converted by CYPs to reactive metabolites. Such inhibition of CYP3A4 can be due to the chemical modification of the heme, the protein, or both as a result of covalent binding of modified heme to the protein. The inactivation of CYP3A4 by drugs has important clinical significance as it metabolizes approximately $60 \%$ of therapeutic drugs, and its inhibition frequently causes unfavorable drug-drug interactions and toxicity. The clinical outcomes due to CYP3A4 inactivation depend on many factors associated with the enzyme, drugs, and patients. Clinical professionals should adopt proper approaches when using drugs that are mechanism-based CYP3A4 inhibitors. These include early identification of drugs behaving as CYP3A4 inactivators, rational use of such drugs (eg, safe drug combination regimen, dose adjustment, or discontinuation of therapy when toxic drug interactions occur), therapeutic drug monitoring, and predicting the risks for potential drug-drug interactions. A good understanding of CYP3A4 inactivation and proper clinical management are needed by clinical professionals when these drugs are used.
\end{abstract}

Keywords: mechanism-based inhibition, CYP3A4, drug-drug interactions, toxicity

\section{Introduction}

The human cytochrome P450 (CYP) 3A subfamily, includes CYP3A4, 3A5, 3A7 (Nelson et al 1996), and 3A43 (Domanski et al 2001). CYP3A4 is most abundant in the human liver $(\sim 40 \%)$ and metabolizes more than $50 \%$ of clinically used drugs (Shimada et al 1994; Rendic and Di Carlo 1997). Significant interindividual variability in the expression and activity of CYP3A4 has also been observed (Shimada et al 1994; Thummel et al 1994; von Richter et al 2004; Watanabe et al 2004). Such a substantial variability is considered to be a result of environmental, physiological, and genetic factors (Gibson et al 2002). CYP3A4 is known to metabolize a large variety of compounds varying in molecular weight from lidocaine $(\mathrm{Mr}=234)$ to cyclosporine $(\mathrm{Mr}=1203)$ (Guengerich 1999; Rendic 2002). It is also subjected to reversible and mechanism-based inhibition by a number of drugs. The latter involves the inactivation of the enzyme via the formation of metabolic intermediates (MIs) that bind tightly and irreversibly to the enzyme (Silverman 1988; Kent et al 2001). Mechanism-based inactivation of CYP3A4 by drugs can be due to the chemical modification of the heme, the protein, or both as a result of covalent binding of modified heme to the protein (Osawa and Pohl 1989; Ortiz de Montellano and Correia 1995; Silverman 1998).

A mechanism-based inhibition of CYP3A4 is characterized by NADPH-, timeand concentration-dependent enzyme inactivation and substrate protection (Ito et al 
1998b; Silverman 1998). Human liver microsomes, cDNAexpressed enzyme, and hepatocytes are commonly used in in-vitro models for the investigation of mechanism-based inhibition of CYP3A4 (Silverman 1998). Important kinetic parameters for mechanism-based inhibition such as $K_{\mathrm{I}}$ (the concentration required for half-maximum inactivation), $k_{\text {inact }}$ (the rate constant of maximum inactivation at saturation, analogous to $\left.\mathrm{V}_{\max }\right)$, and partition ratio $\left(R_{\max }\right.$, ratio of moles of substrate activation per mole of enzyme inactivation) can be determined using in vitro models. However, in vivo animal and human studies are usually needed to explore the clinical importance of CYP3A4 inactivation.

CYP3A4 inactivators such as delavirdine (Voorman et al 1998), L-754,394 (Lightning et al 2000), $17 \alpha-$ ethynylestradiol (Lin et al 2002), and midazolam (Schrag and Wienkers 2001; Khan et al 2002) possibly bind covalently to the CYP apoprotein and inactivate it. On the other hand, certain CYP3A4 inactivators such as macrolides, eg, erythromycin (Franklin 1991), glabridin (Kent et al 2002), and nelfinavir (Lillibridge et al 1998) bind the heme and inactivate the enzyme. In addition, the reactive intermediates of acetylenic compounds formed by several CYPs have been known to alkylate the prosthetic heme group as well as to bind covalently to the protein (Ortiz de Montellano and Correia 1995). The aim of this review is to highlight the clinical outcomes and management of mechanism-based inhibition of CYP3A4.

\section{Clinical outcomes of mechanism- based inhibition of CYP3A4 \\ Pharmacokinetic drug-drug interactions}

Due to the key role of CYP3A4 in drug metabolism, significant inactivation of this enzyme could result in marked pharmacokinetic drug-drug interactions. The in vivo inhibitory effect of a mechanistic inactivator is more prominent after multiple dosing and lasts longer than that of a reversible inhibitor (Lin and Lu 1998). The activated species irreversibly alters the enzyme to remove it permanently from the pool of active enzyme. Pharmacokinetic interactions often occur as a result of a change in drug metabolism.

For example, diltiazem as a CYP3A4 inactivator has been shown to potently inhibit the metabolism of a variety of coadministered drugs including carbamazepine (Brodie and Macphee 1986), cyclosporine (Brockmöller et al 1990; Sadrieh and Thomas 1994), quinidine (Laganière et al 1996), midazolam (Backman et al 1994), alfentanil (Ahonen et al
1996), nifedipine (Toyosaki et al 1988), and lovastatin (Azie et al 1998). Inhibition of CYP3A by ritonavir explains, at least in part, the remarkable elevation of blood concentrations and area under the plasma concentrationtime curve (AUC) of concomitantly administered drugs including rifabutin (Cato et al 1998), clarithromycin (Ouellet et al 1998), ketoconazole (Hsu et al 1998), saquinavir (Hsu et al 1998a), amprenavir (Sadler et al 2001; Goujard et al 2003), and nelfinavir (Hsu et al 1998; Kurowski et al 2002).

Pharmacokinetic studies have indeed revealed specific interactions between erythromycin and cyclosporine (Vereerstraeten et al 1987), cisapride (Jenkins and Gibson 1996; Michalets and Williams 2000; Kyrmizakis et al 2002), pimozide (Rubinstein 2001), disopyramide (Ragosta et al 1989), lidocaine (Isohanni et al 1998, 1999), theophylline (Hemsworth and Renton 1981), astemizole (Klausner 1999), carbamazepine (Zitelli et al 1987; Tagawa et al 1989; Turner and Renton 1989; Mota et al 1996), midazolam (Yeates et al 1997), triazolam (Greenblatt et al 1998), alprazolam (Yasui et al 1996), alfentanil (Bartkowski et al 1989), mosapride (Katoh et al 2003), digoxin (Tsutsumi et al 2002), and warfarin (Bussey et al 1985; Weibert et al 1989).

Inhibition of CYP3A by ritonavir partly explains the remarkable elevation of blood concentrations and AUC of concomitantly administered drugs that are extensively metabolized by CYP3A4 and have intermediate $(10-80 \mathrm{~L} / \mathrm{h})$ to high $(>80 \mathrm{~L} / \mathrm{h})$ intrinsic clearance and significant firstpass metabolism. These drugs include rifabutin $(400 \%$ increase) (Cato et al 1998), clarithromycin (77\%) (Ouellet et al 1998), ketoconazole (350\%) (Hsu et al 1998), saquinavir (5000\%) (Hsu et al 1998a), amprenavir (210\%) (Sadler et al 2001), nelfinavir (152\%) (Hsu et al 1998; Kurowski et al 2002), ABT-378 (7700\%) (Sham et al 1998), and indinavir (380\%) (Hsu et al 1998b). The large increase in the plasma concentration of other protease inhibitors when coadministered with ritonavir provides the basis of rational dual protease inhibitor regimens, resulting in reduced doses and less frequent dosage intervals.

The functional effects of CYP3A4 inactivation on the pharmacokinetic behavior of the inhibitor itself or that of coadministered drugs are complex and depend on factors that are associated both with drugs and patients. The downstream consequences (efficacy or toxicity) of CYP3A4 inhibition may or may not parallel the pharmacokinetic alterations. Importantly, mechanism-based CYP3A4 inactivation causes long-term effects on drug pharmacokinetics, as the inactivated CYP3A4 has to be replaced by newly synthesized CYP3A4 protein. 
It is believed that the in vivo inhibitory effect of a mechanistic inactivator is more prominent after multiple dosing and lasts longer than that of a reversible inhibitor (Lin and Lu 1998). The activated species irreversibly alters the enzyme to remove it permanently from the pool of active enzyme. Thus, the time-dependent inactivation of CYP3A enzymes would result in nonlinear pharmacokinetics, as exemplified by $50 \%-100 \%$ prolongation of the diltiazem half-life in humans after chronic dosing compared with the single-dose effects (Tsao et al 1990). Certainly, in addition to enzyme inactivation, other mechanisms may also play a role in the prolonged $t_{1 / 2 \beta}$. These include reversible inhibition of CYP3A by diltiazem and its metabolites, interactions of diltiazem with its metabolites, change of plasma protein binding, and possible involvement of drug transporters such as PgP. By investigating the pharmacokinetic interactions between diltiazem and its metabolites, and with model PgP inhibitors, identifying the contributions of these alternative mechanisms is likely.

The extent of drug interaction due to CYP3A inactivation will be time-dependent in both its onset and offset. For example, erythromycin did not significantly inhibit the clearance of alfentanil on the first day of coadministration but produced a 25\% decrease after 7 days (Bartkowski et al 1989). As the half-life for the onset of inactivation is inversely proportional to the efficiency $\left[k_{\text {inact }} /\left(K_{\mathrm{I}}+[I]\right)\right]$ of inactivation, the delayed onset of inhibition by erythromycin is a predictable property of a relatively weak inactivator. The delayed termination of CYP3A inhibition is expected to be independent of the inactivating drug and the extent of inhibition. This time-dependent termination may explain the serious adverse events associated with discontinuation of the irreversible inactivator, mibefradil, and the need for immediate initiation of alternative calcium-channel blocker treatment (Mullins et al 1998; Prueksaritanont et al 1999). A mibefradil washout period of 7-14 days is therefore recommended.

\section{Drug toxicities}

Mechanism-based inactivation of CYP3A4 may cause severe drug toxicity through the enhanced exposure to coadministered drugs (Dresser et al 2000). For example, when irreversible CYP3A4 inhibitors such as erythromycin or clarithromycin are coadministered with terfenadine, astemizole, or pimozide patients may experience Torsades de pointes (a life-threatening ventricular arrhythmia associated with QT prolongation) (Spinler et al 1995;
Dresser et al 2000; Michalets and Williams 2000). Terfenadine is a CYP3A4 substrate that undergoes extensive first-pass metabolism following oral administration (Honig et al 1992; Jurima-Romet et al 1994). Normally, the carboxylate metabolite of terfenadine is the principal circulating entity in plasma, whereas unchanged terfenadine is not present at measurable concentrations (Honig et al 1992, 1993). Furthermore, rhabdomyolysis has been observed when simvastatin was combined with erythromycin or ritonavir (Williams and Feely 2002). Symptomatic hypotension may occur when mechanismbased CYP3A4 inhibitors are combined with some dihydropyridine calcium antagonists (Anderson and Nawarskas 2001), as well as with the phosphodiesterase inhibitor, sildenafil (Simonsen 2002). In addition, ataxia can occur when carbamazepine is coadministered with mechanism-based CYP3A4 inhibitors such as macrolide antibiotics, isoniazid, verapamil, or diltiazem (Spina et al 1996; Patsalos et al 2002).

Mibefradil (Posicor) was launched for the long-term therapy of patients with hypertension in the United States in 1997, but was voluntarily withdrawn from the market in June 1998 due to potential toxic drug interactions. Severe drug interactions of mibefradil (a mechanism-based CYP3A4 inhibitor) have been reported with $\beta$-blockers (Mullins et al 1998), digoxin (Siepmann et al 1995), methylprednisolone (Varis et al 2000), verapamil (Mullins et al 1998; Welker et al 1998), diltiazem (Mullins et al 1998; Welker et al 1998), cyclosporine (Spoendlin et al 1998), simvastatin (Schmassmann-Suhijar et al 1998; Welker et al 1998), and tacrolimus (Krahenbuhl et al 1998). For example, 4 cases of life-threatening cardiogenic shock have been reported in patients taking mibefradil and $\beta$-blockers, who also began taking dihydropyridine calcium channel blockers (Mullins et al 1998). One case resulted in death, and the other 3 survived episodes of cardiogenic shock with intensive support of heart rate and blood pressure. Cases of myopathy, including rhabdomyolysis, have been reported in patients with hypertension taking simvastatin concomitantly with mibefradil (Schmassmann-Suhijar et al 1998; Muck 2000). These drug interactions often resulted in increased plasma concentrations of coadministered drugs and/or severe toxicity.

\section{Immune responses}

In addition to toxic drug-drug interactions, the formation of drug-modified CYP3A can also play a role in the initiation 
of toxicity. The formed adduct can act as a hapten and induce potential immune responses, leading to anti-CYP3A autoantibody production. The formation of drug-CYP3A adducts may thus be either nontoxic, or rarely fatal, depending on the drugs, the kinetics of adduct formation and degradation, other affected target proteins and organs, and the pathological conditions of the patients (Chitturi and George 2002). The reactivity of drug intermediates, the subcellular localization of major protein targets, and the primary interactions between metabolite and protein are important determining factors of toxicity (Pumford and Halmes 1997; Tornqvist et al 2002). Selective protein covalent binding by drugs or metabolites has been associated with target organ/tissue toxicity of drugs (Cohen et al 1997), although the underlying mechanisms are still incompletely known for most drugs.

Studies to reveal the role of drug reactive metabolites and their protein-adducts (eg, modified CYP3A4) in the mechanism of drug-induced idiosyncratic reactions are lacking. Mostly the proposed mechanism is based on the so-called hapten hypothesis, which requires drug bioactivation, covalent binding to proteins followed by uptake, antigen processing, and a polyclonal immune response (Naisbitt et al 2001; Ju and Uetrecht 2002; Pirmohamed et al 2002). The recently proposed "danger hypothesis" by Pirmohamed et al (2002; Naisbitt et al 2003), which hypothesizes that the immune system only responds to danger signals, can be considered to be additive to the hapten hypothesis. Thus, stimulation of an immune response to a drug-protein adduct (signal 1) requires the presence of co-stimulatory signals and cytokines (signals 2 and 3 ), which propagate and determine the type of immune response. For example, in acetaminophen (APAP) toxicity, covalent binding of N-acetyl-p-benzoquinone (NAPQI) to proteins (signal 1) may induce the production of nitric oxide (signal 2) due to the activation of Kupffer cells, which then scavenges superoxide to produce peroxynitrite (signal 3), leading to protein nitration and tissue injury (Jaeschke et al 2002). The nature of the danger signal is poorly defined, as some drug-protein adducts are not toxic in vivo.

\section{Factors affecting the clinical outcomes of mechanism-based CYP3A4 inhibition}

The clinical outcomes due to CYP3A4 inactivation depend on many factors associated with the enzyme, drugs, and patients. The interindividual variations in enzyme activity, polypharmacy, diseases, and genetic factors are all potentially important factors affecting the outcomes of mechanism-based inactivation of CYP3A4. In most cases, there are remarkable interindividual variations in the mechanism-based inactivation of CYP3A4 and subsequent drug-drug interactions. This is mainly due to the significant differences in the hepatic expression of CYP3A4, based on both in vitro (35-100-fold) studies with a human liver bank (Shimada et al 1994) and in vivo (20-50-fold) studies with probe drugs such as erythromycin (Watkins 1994), midazolam (Thummel et al 1994), and alfentanil (Kharasch et al 2003). The expression of CYP3A can also be influenced by inflammation and proinflammatory cytokines, which are known to affect drug metabolism by downregulating or upregulating expression of several CYPs, including the CYP3A subfamily. However, it appears that there are no marked age and gender differences in CYP3A4 expression (Hunt et al 1992; Schmucker 2001; Meibohm et al 2002), although 24\%-36\% higher activity in females has been reported (Watkins et al 1989). Changes in liver size and blood flow, renal function, and drug-protein binding and distribution with aging may be significant variables that can affect drug metabolism and elimination. Thus, age and gender may be important factors determining the clinical outcome of drug interactions involving CYP3A4 inactivation.

Intestinal CYP3A4 inactivation is also an important factor modulating the clinical outcomes of CYP3A4 inactivation. For example, oral administration of clarithromycin for one week resulted in an AUC ratio (ie, pretreatment AUC/post-treatment AUC) for intravenous midazolam of 0.33 , but the ratio was 0.16 for oral midazolam (Gorski et al 1998). This greater extent of interaction observed after oral administration is consistent with the intestinal availability of approximately 0.4 for midazolam and a complete inactivation of intestinal CYP3A by clarithromycin (Gorski et al 1998). Such a complete inactivation of intestinal CYP3A is consistent with the estimates of $k_{\text {inact }}$ and $K_{\mathrm{I}}$ and the relatively high concentrations of clarithromycin expected in the intestinal lumen. The impact of inactivation of intestinal wall CYP3A depends on the values of the inactivation parameters, the residence time of the inhibitor at the site ofCYP3A, and the relative contribution of intestinal and hepatic metabolism to the first-pass metabolism of a given drug.

The clinical consequences of mechanism-based CYP3A4 inhibition depend upon additional factors. Such factors include variations in concentration-time course, 
Table I Drugs as mechanism-based CYP3A4 inhibitors

\begin{tabular}{|c|c|c|c|c|}
\hline Drug & $\begin{array}{r}k_{\text {inact }} \\
\left(\mathrm{min}^{-1}\right)\end{array}$ & $\begin{array}{r}K_{1} \\
(\mu M)\end{array}$ & $\begin{array}{l}\text { Interacting drugs } \\
\text { (examples) }\end{array}$ & Reference \\
\hline Antibiotics & & & & Tinel et al I989; Mayhew et al 2000 \\
\hline Clarithromycin & 0.072 & 5.49 & Cyclosporine, cisapride, etc & \\
\hline Erythromycin & 0.08 & 46.6 & Cyclosporine, cisapride, etc & $\begin{array}{l}\text { Chan and Delucchi 2000; Kanamitsu et al 2000; } \\
\text { Yamano et al 200I }\end{array}$ \\
\hline Isoniazid & 0.08 & 228 & Triazolam, diazepam, etc & Wen et al 2002 \\
\hline Troleandomycin & 0.15 & 0.18 & Carbamazepine, triazolam, etc & $\begin{array}{l}\text { Pessayre et al I983; Miura et al 1989; Tinel et al I989; } \\
\text { Chan and Delucchi } 2000\end{array}$ \\
\hline \multicolumn{5}{|l|}{ Anticancer drugs } \\
\hline Irinotecan & 0.06 & 24 & Unknown & Hanioka et al 2002 \\
\hline SN-38 & 0.10 & 26 & Unknown & Hanioka et al 2002 \\
\hline Tamoxifen & 0.051 & 0.2 & Theophylline, warfarin & Zhao et al 2002 \\
\hline N-desmethyltamoxifen & 0.08 & 2.6 & Unknown & Zhao et al 2002 \\
\hline \multicolumn{5}{|l|}{ Anti-HIV agents } \\
\hline Amprenavir & 0.073 & 1.4 & Ritonavir & von Moltke et al 2000 \\
\hline Delavirdine & 0.44 & 9.5 & Rifampicin & Voorman et al 1998 \\
\hline DPC 68I & 0.22 & 0.24 & Unknown & Luo et al 2003 \\
\hline L-754,394 & 1.62 & 7.5 & Unknown & Chiba et al 1995; Lightning et al 2000 \\
\hline Nelfinavir & 0.18 & 5.6 & Delavirdine, zidovudine, etc & Lillibridge et al 1998 \\
\hline Ritonavir & 0.078 & 0.07 & Clarithromycin, ketoconazole, etc & Koudriakova et al 1998; von Moltke et al 2000 \\
\hline \multicolumn{5}{|l|}{ Antihypertensive agents } \\
\hline Dihydralazine & 0.05 & 35 & Unknown & Masubuchi and Horie 1999 \\
\hline Diltiazem & 0.11 & 2.0 & Cyclosporine, midazolam, etc & $\begin{array}{l}\text { Jones et al I999; Ma et al 2000; Mayhew et al 2000; } \\
\text { Yeo and Yeo 200I }\end{array}$ \\
\hline N-desmethyl diltiazem & 0.027 & 0.77 & Unknown & Mayhew et al 2000 \\
\hline Mibefradil & 0.40 & 2.3 & Cyclosporine, verapamil, etc & Prueksaritanont et al 1999 \\
\hline Nicardipine & 2.0 & 0.6 & Metoprolol, cyclosporine, etc & Ma et al 2000 \\
\hline Verapamil & 0.09 & 1.7 & Midazolam, diltiazem, etc & Ma et al 2000; Yeo and Yeo 200I \\
\hline \multicolumn{5}{|l|}{ Steroids and their modulators } \\
\hline I7 $\alpha$-Ethynylestradiol & 0.04 & 18 & Imipramine, alprazolam, etc & Lin et al 2002 \\
\hline Gestodene & 0.40 & 46 & Imipramine, alprazolam, etc & Guengerich 1990 \\
\hline Mifepristone & 0.089 & 4.7 & Unknown & He et al 1999 \\
\hline Raloxifene & 0.16 & 9.9 & Warfarin & Chen et al 2002 \\
\hline \multicolumn{5}{|l|}{ Herbal constituents } \\
\hline Bergamottin & 0.30 & 4.2 & Grapefruit juice-drug interactions & He et al 1998; Eagling et al 1999 \\
\hline 6', 7'-Dihydroxybergamottin & 0.16 & 59 & Grapefruit juice-drug interactions & Schmiedlin-Ren et al 1997 \\
\hline Glabridin & 0.14 & 7.0 & Unknown & Kent et al 2002 \\
\hline Oleuropein & 0.09 & 22.2 & Unknown & Stupans et al 200I \\
\hline Resveratrol & 0.20 & 20 & Unknown & Chan and Delucchi 2000 \\
\hline Silybin & 0.06 & 32 & Indinavir, metronidazole & Sridar et al 2004 \\
\hline \multicolumn{5}{|l|}{ Miscellaneous } \\
\hline Diclofenac & 0.246 & 1640 & Nateglinide, quinidine, etc & Masubuchi et al 2002 \\
\hline Fluoxetine & 0.017 & 5.26 & Olanzapine, alprazolam & Mayhew et al 2000 \\
\hline (-)-Hydrastine & 0.23 & 110 & Unknown & Chatterjee and Franklin 2003 \\
\hline KIIOO2 & 0.026 & 0.5 & Unknown & Jacobsen et al 2000 \\
\hline KII777 & 0.054 & 0.06 & Unknown & Jacobsen et al 2000 \\
\hline Midazolam & 0.15 & 5.8 & Diltiazem, verapamil, etc & Khan et al 2002 \\
\hline Tabimorelin & 0.08 & 4.7 & Midazolam & Zdravkovic et al 2003 \\
\hline
\end{tabular}

Abbreviations: $K_{1}$, the half-maximal rate of inactivation; $k_{\text {inact }}$, the maximal rate constant of inactivation at saturation. 
plasma protein binding, atypical substrate kinetics for CYP3A4, existence of multiple inhibitory metabolites, partitioning from plasma to liver, rate-limiting active transport of drug and inhibitor into the hepatocytes, intestinal active efflux of drug, and inhibitor and extrahepatic metabolism of drugs and inhibitors.

\section{Clinical management of mechanism-based inhibition of CYP3A4}

The inactivation of CYP3A4 by drugs has important clinical implications since CYP3A4 metabolizes approximately $60 \%$ of therapeutic drugs, and its inhibition frequently causes unfavorable drug-drug interactions and toxicity. A good understanding of CYP3A4 inactivation and proper clinical management are needed by clinical professionals when these drugs are used.

\section{Identification of drugs causing irreversible CYP3A4 inhibition}

A number of drugs with widely differing structures and therapeutic targets have been reported to be mechanismbased inhibitors of CYP3A4 (Table 1). The identification of drugs causing irreversible CYP3A4 inhibition and the mechanisms involved are important in terms of rational use of therapeutic drugs. Mechanism-based inhibition of CYP3A4 can decrease a drug's first-pass clearance in the liver and greatly alter the kinetic behavior. Moreover, the decrease in functional catalytic activity of the damaged CYP can lead to enhanced exposure of other drugs that are normally cleared by CYP3A4, thus setting the stage for potential drug-drug interactions. It is therefore not surprising that during drug development new compounds that are potent CYP3A4 inhibitors are regarded with high skepticism and often withdrawn from further development.

Early and timely identification of candidate drugs that inactivate CYP3A4 is important in drug development, as this can save large expenditures in time and money. In cases where new drugs have already been launched, and where a large population of patients has been exposed to the drug, severe interactions and even fatal toxicity may occur. Therefore, lessons should be learned from such cases (eg, mibefradil) where a drug was withdrawn from the market due to an unacceptable risk of potentially dangerous drug-drug interactions resulting from CYP3A inactivation. With the current techniques, it is increasingly possible to predict which new drugs will be associated with the formation of reactive metabolites and CYP3A inactivation. By screening drug candidates for possible formation of reactive metabolic intermediates (MIs) that inhibit CYP3A4 in an irreversible manner, and by establishing structureactivity relationships, it is possible to identify and eliminate such chemicals at an early stage of development. The application of genomic and proteomic approaches to the study of drug-CYP interactions, as well as the use of heterogeneous expression systems for specific CYPs including CYP3A4, has the potential to lead to a more effective screen due to a high-throughput capacity.

So far, the identified clinically important mechanismbased CYP3A4 inhibitors include antibiotics (eg, clarithromycin, erythromycin, and isoniazid), anticancer agents (eg, irinotecan and tamoxifen), anti-HIV agents (eg, ritonavir and delavirdine), antihypertensives (eg, verapamil and diltiazem), and steroids and their modulators (eg, gestodene and mifepristone). Most of these CYP3A4 inactivators are also substrates and inducers of CYPs (in particular CYP3A4). The drugs that inactivate CYP3A4 often possess a number of structural similarities such as a tertiary amine function, a furan ring, and an acetylene functional group. It appears that the chemical properties of a drug critical for CYP3A4 inactivation include: (1) being a CYP substrate; (2) formation of reactive metabolites; (3) preponderance of CYP inducers; and (4) being a Pglycoprotein (PgP) substrate.

\section{Rational use of drugs as mechanism- based CYP3A4 inhibitors}

Several drugs (eg, mibefradil) that have been identified as CPY3A4 inactivators have been withdrawn from the market due to reported toxic drug-drug toxicities. However, a number of drugs that behave as mechanism-based CYP3A4 inhibitors are still in use by clinical doctors. Caution should be taken when these drugs are used, particularly when used in combination with other drugs that are CYP3A4 substrates and have narrow therapeutic indices.

Mechanism-based CYP3A4 inhibitors that have been reported to cause significantly increased systemic exposure of coadministered drugs and/or severe drug toxicity should be avoided. For example, it is known that erythromycin can cause Torsades de pointes when coadministered with terfenadine, cisapride, or astemizole (all CYP3A4 substrates) (Spinler et al 1995; Dresser et al 2000; Michalets 
and Williams 2000), and should therefore be avoided in these combinations.

In some instances, proper dose adjustment or alternative drugs may be needed when a CYP3A4 inactivator is combined with another drug. For example, isoniazid, a mechanism-based CYP3A4 inhibitor (Wen et al 2002), markedly increased serum phenytoin concentrations, with resultant toxicity in some patients (Kutt et al 1968; Miller et al 1979). Isoniazid also potentiated acetaminophen hepatotoxicity (Crippin 1993; Nolan et al 1994). One case of increased warfarin toxicity (at $10 \mathrm{mg} /$ day) including increased prothrombin time, hematuria, and bleeding gums caused by isoniazid has also been reported (Self et al 1999). Such interactions will require a reduced dose of coadministered drugs or replacement of drugs with similar efficacy while maintaining the isoniazid therapy.

\section{Role of therapeutic drug monitoring}

Monitoring plasma concentrations of concurrently administered drugs that are CYP3A4 substrates and/or have narrow therapeutic indices, and observing for signs of clinical toxicity are necessary for the early identification of potential drug-drug interactions and subsequent toxicities.

Tamoxifen, a nonsteroidal antiestrogen used for adjuvant chemotherapy of all stages of hormone-dependent breast cancer, is a potent mechanism-based CYP3A4 inhibitor (Zhao et al 2002). However, clinical data on tamoxifendrug interactions are scant. A potential life-threatening interaction (Lodwick et al 1987; Ritchie and Grant 1989; Tenni et al 1989) may occur when tamoxifen is combined with warfarin, a substrate for CYP2C9, 2C19, and 3A4 (Komatsu et al 2000). Prothrombin time doubled in a few cases and subdural hematoma developed. It is believed that CYP inhibition is likely to be the major mechanism for this interaction, while displacement of protein binding may just play a minor role. Thus, the plasma concentration of warfarin and prothrombin time should be carefully monitored when tamoxifen is coadministered with warfarin.

Herbal components may also behave as mechanismbased CYP3A4 inhibitors. Silybin, the major constituent of milk thistle (Sylybum marianum), is a mechanism-based inhibitor of CPY3A4 (Sridar et al 2004). Treatment of milk thistle at $175 \mathrm{mg}$ (equivalent to silymarin $153 \mathrm{mg}$ ) 3 times per day for 3 weeks caused a $9 \%$ and $25 \%$ reduction in the AUC and mean trough level of indinavir, respectively $(\mathrm{C} 8$, the concentration at 8 hours) in healthy volunteers (Piscitelli et al 2002). Therefore, monitoring plasma indinavir concentrations may be required when patients also take milk thistle.

\section{Predicting risks for drug-drug interactions involving CYP3A4 inactivation}

It may be necessary to assess the clinical risks by predicting qualitatively and quantitatively drug-drug interactions involving CYP3A4 inactivation. Generally, it can be anticipated that the inactivation of CYP3A4 by various drugs would increase the bioavailability of coadministered drugs that are primarily metabolized by CYP3A4, due to intestinal and/or hepatic inhibition of CYP3A4. Compared with reversible inhibition of CYP3A4, mechanism-based inhibitors of CYP3A4 more frequently cause pharmacokinetic-pharmacodynamic drug-drug interactions, as the inactivated CYP3A4 has to be replaced by newly synthesized CYP3A4 protein. The resultant drug interactions may lead to adverse drug effects, including some fatal events.

The accurate interpretation and extrapolation of in vitro interaction data requires a good understanding of pharmacokinetic principles. If the elimination of a drug is mainly by the liver, the total clearance is approximately equal to the hepatic clearance. For low-clearance drugs, a metabolism-based drug interaction will result in an almost proportional decrease in their clearance. On the other hand, if the intrinsic clearance is high, then the hepatic clearance is limited by the hepatic blood flow. Thus, for high-clearance drugs, a decrease in the intrinsic clearance caused by drug interaction has little effect on their hepatic clearance. However, the in vitro inhibitory potency of mechanismbased CYP3A4 inhibitors does not necessarily translate directly into relative extents of inhibition in vivo.

Determination of in vitro kinetic parameters is essential for the prediction of drug metabolism by a particular CYP in vivo. The apparent $K_{\mathrm{I}}$ values for competitive inhibition determined in vitro, together with its relationship to unbound plasma concentrations of the inhibitor achieved with therapeutic doses in vivo, can be used as a rough guide to predict the possibility of a significant in vivo drug interaction (Ito et al 1998a, 1998b). Relating the in vitro results to in vivo pharmacokinetics is not straightforward. Generally, to quantitatively predict the degree of interaction observed in clinical cases, it is necessary to investigate the correlation between in vitro inhibitory potency of the inhibitor and in vivo inhibition, taking into account the distribution of the 
inhibitor into the liver, and extrapolation of data from animal studies (Yamano et al 2001).

\section{Conclusions and future perspectives}

The broad substrate selectivity makes CYP3A4 susceptible to relatively frequent reversible or irreversible (mechanismbased) inhibition by a wide variety of drugs. Irreversible inhibition of CYP3A4 due to enzyme inactivation or complexation occurs when some therapeutic drugs are converted by CYPs to reactive metabolites capable of covalently binding to CYP3A4 protein or heme moiety. Mechanism-based inhibition of CYP3A4 is characterized by NADPH-, time-, and concentration-dependent enzyme inactivation. A number of therapeutic drugs have been identified as mechanism-based CYP3A4 inhibitors.

Due to the key role of CYP3A4 in drug metabolism, inactivation of this enzyme could result in marked pharmacokinetic drug-drug interactions and/or toxicities. The clinical outcome of any drug-drug interaction due to CYP3A4 inactivation depends on a number of factors that are associated with both the administered drugs and patients, and the pharmacodynamic consequences may or may not closely follow pharmacokinetic alterations. Since many mechanism-based CYP3A4 inhibitors are also inducers of CYPs, and because enzyme inactivation is significantly affected by drug exposure time, the clearance of coadministered drugs may be increased or decreased in vivo, depending on the interplay between substrate, inhibitor, inducer, and CYP3A4. Thus, detailed studies are often needed to characterize these drugs and their potential drugdrug interactions.

Clinicians should adopt proper strategies when using drugs that are mechanism-based CYP3A4 inhibitors. Early identification of drugs behaving as CYP3A4 inactivators and the mechanism involved is important. If these drugs have to be used in some instances, rational use of such drugs becomes necessary, including the use of a safe drug combination regimen, dose adjustment, and discontinuation of therapy when toxic drug interactions occur. When combined with drugs with narrow therapeutic indices, the monitoring of plasma drug concentrations and observing of potential toxicities should be conducted. Predicting the risks for potential drug-drug interactions following proper pharmacokinetic principles and in vitro-in vivo extrapolation is likely. A good understanding of CYP3A4 inactivation and proper clinical management are needed by clinical professionals when these drugs are used.

\section{Acknowledgments}

The authors appreciate the support by the National University of Singapore Academic Research Funds.

\section{Abbreviations}

AUC, area under the plasma concentration-time curve; $\mathrm{C}_{\max }$, maximum plasma concentration; CL, clearance; CYP, cytochrome P450; $\mathrm{E}_{\text {inact }}$, inactivation efficiency; $K_{\mathrm{i}}$, apparent inhibition constant; $K_{\mathrm{I}}$, the concentration required for half-maximum inactivation; $K_{\text {inact }}$, the maximum rate of inactivation at saturation; PgP, P-glycoprotein; $t_{1 / 2 \beta}$, elimination half-life; $t_{1 / \text { inact }}$, inactivation half-life.

\section{References}

Ahonen J, Olkkola KT, Salmenperä M, et al. 1996. Effect of diltiazem on midazolam and alfentanil disposition in patients undergoing coronary artery bypass grafting. Anesthesiology, 85:1246-51.

Anderson JR, Nawarskas JJ. 2001. Cardiovascular drug-drug interactions. Cardiol Clin, 19:215-34.

Azie NE, Brater DC, Becker PA, et al. 1998. The interaction of diltiazem with lovastatin and pravastatin. Clin Pharmacol Ther, 64:369-77.

Backman JT, Olkkola KT, Aranko K, et al. 1994. Dose of midazolam should be reduced during diltiazem and verapamil treatments. $\mathrm{Br} J$ Clin Pharmacol, 37:221-5.

Bartkowski RR, Goldberg ME, Larijani GE, et al. 1989. Inhibition of alfentanil metabolism by erythromycin. Clin Pharmacol Ther, 46: 99-102.

Brockmöller J, Neumayer H-H, Wagner K, et al. 1990. Pharmacokinetic interaction between cyclosporin and diltiazem. Eur J Clin Pharmacol, 38:237-42.

Brodie MJ, Macphee GJA. 1986. Carbamazepine neurotoxicity precipitated by diltiazem. $B M J, 292: 1170-1$.

Bussey HI, Knodel LC, Boyle DA. 1985. Warfarin-erythromycin interaction. Arch Intern Med, 145:1736-7.

Cato Ard, Cavanaugh J, Shi H, et al. 1998. The effect of multiple doses of ritonavir on the pharmacokinetics of rifabutin. Clin Pharmacol Ther, 63:414-21.

Chan WK, Delucchi AB. 2000. Resveratrol, a red wine constituent, is a mechanism-based inactivator of cytochrome P450 3A4. Life Sci, 67:3103-12.

Chatterjee P, Franklin MR. 2003. Human cytochrome p450 inhibition and metabolic-intermediate complex formation by goldenseal extract and its methylenedioxyphenyl components. Drug Metab Dispos, 31: 1391-7.

Chen Q, Ngui JS, Doss GA, et al. 2002. Cytochrome P450 3A4-mediated bioactivation of raloxifene: irreversible enzyme inhibition and thiol adduct formation. Chem Res Toxicol, 15:907-14.

Chiba M, Nishime JA, Lin JH. 1995. Potent and selective inactivation of human liver microsomal cytochrome P-450 isoforms by L-754,394, an investigational human immune deficiency virus protease inhibitor. J Pharmacol Exp Ther, 275:1527-34.

Chitturi S, George J. 2002. Hepatotoxicity of commonly used drugs: nonsteroidal anti-inflammatory drugs, antihypertensives, antidiabetic agents, anticonvulsants, lipid-lowering agents, psychotropic drugs. Semin Liver Dis, 22:169-83.

Cohen SD, Pumford NR, Khairallah EA, et al. 1997. Selective protein covalent binding and target organ toxicity. Toxicol Appl Pharmacol, 143:1-12.

Crippin JS. 1993. Acetaminophen hepatotoxicity: potentiation by isoniazid. Am J Gastroenterol, 88:590-5.

Domanski TL, Finta C, Halpert JR, et al. 2001. cDNA cloning and initial characterization of CYP3A43, a novel human cytochrome P450. Mol Pharmacol, 59:386-92. 
Dresser GK, Spence JD, Bailey DG. 2000. Pharmacokineticpharmacodynamic consequences and clinical relevance of cytochrome P450 3A4 inhibition. Clin Pharmacokinet, 38:41-57.

Eagling VA, Profit L, Back DJ. 1999. Inhibition of the CYP3A4-mediated metabolism and P-glycoprotein-mediated transport of the HIV-1 protease inhibitor saquinavir by grapefruit juice components. Br J Clin Pharmacol, 48:543-52.

Franklin MR. 1991. Cytochrome P450 metabolic intermediate complexes from macrolide antibiotics and related compounds. Methods Enzymol, 206:559-73.

Gibson GG, Plant NJ, Swales KE, et al. 2002. Receptor-dependent transcriptional activation of cytochrome P4503A genes: induction mechanisms, species differences and interindividual variation in man. Xenobiotica, 32:165-206.

Gorski JC, Jones DR, Haehnerdaniels BD, et al. 1998. The contribution of intestinal and hepatic CYP3A to the interaction between midazolam and clarithromycin. Clin Pharmacol Ther, 64:133-43.

Goujard C, Vincent I, Meynard JL, et al. 2003. Steady-state pharmacokinetics of amprenavir coadministered with ritonavir in human immunodeficiency virus type 1-infected patients. Antimicrob Agents Chemother, 47:118-23.

Greenblatt DJ, von Moltke LL, Harmatz JS, et al. 1998. Inhibition of triazolam clearance by macrolide antimicrobial agents: in vitro correlates and dynamic consequences. Clin Pharmacol Ther, 64: 278-85.

Guengerich FP. 1990. Mechanism-based inactivation of human liver microsomal cytochrome P-450 IIIA4 by gestodene. Chem Res Toxicol, 3:363-71.

Guengerich FP. 1999. Cytochrome P-450 3A4: regulation and role in drug metabolism. Annu Rev Pharmacol Toxicol, 39:1-17.

Hanioka N, Ozawa S, Jinno H, et al. 2002. Interaction of irinotecan (CPT11) and its active metabolite 7-ethyl-10-hydroxycamptothecin (SN38) with human cytochrome P450 enzymes. Drug Metab Dispos, 30:391-6.

He K, Iyer KR, Hayes RN, et al. 1998. Inactivation of cytochrome P450 3A4 by bergamottin, a component of grapefruit juice. Chem Res Toxicol, 11:252-9.

He K, Woolf TF, Hollenberg PF. 1999. Mechanism-based inactivation of cytochrome P-450-3A4 by mifepristone (RU486). J Pharmacol Exp Ther, 288:791-7.

Hemsworth TC, Renton KW. 1981. Depression of theophylline metabolism and elimination by troleandomycin and erythromycin. Biochem Pharmacol, 30:1299-304.

Honig PK, Woosley RL, Zamani K, et al. 1992. Changes in the pharmacokinetics and electrocardiographic pharmacodynamics of terfenadine with concomitant administration of erythromycin. Clin Pharmacol Ther, 52:231-8.

Honig PK, Wortham DC, Zamani K, et al. 1993. Terfenadine-ketoconazole interaction: pharmacokinetic and electrocardiographic consequences. JAMA, 269:1513-18.

Hsu A, Granneman GR, Bertz RJ. 1998. Ritonavir. Clinical pharmacokinetics and interactions with other anti-HIV agents. Clin Pharmacokinet, 35:275-91.

Hsu A, Granneman GR, Cao G, et al. 1998a. Pharmacokinetic interactions between two human immunodeficiency virus protease inhibitors, ritonavir and saquinavir. Clin Pharmacol Ther, 63:453-64.

Hsu A, Granneman GR, Cao G, et al. 1998b. Pharmacokinetic interaction between ritonavir and indinavir in healthy volunteers. Antimicrob Agents Chemother, 42:2784-91.

Hunt CM, Westerkam WR, Stave GM. 1992. Effect of age and gender on the activity of human hepatic CYP3A. Biochem Pharmacol, 44: 275-83.

Isohanni MH, Neuvonen P, Olkkola KT. 1999. Effect of erythromycin and itraconazole on the pharmacokinetics of oral lignocaine. Pharmacol Toxicol, 84:143-6.

Isohanni MH, Neuvonen PJ, Palkama VJ, et al. 1998. Effect of erythromycin and itraconazole on the pharmacokinetics of intravenous lignocaine. Eur J Clin Pharmacol, 54:561-5.
Ito K, Iwatsubo T, Kanamitsu S, et al. 1998a. Quantitative prediction of in vivo drug clearance and drug interactions from in vitro data on metabolism, together with binding and transport. Annu Rev Pharmacol Toxicol, 38:461-99.

Ito K, Iwatsubo T, Kanamitsu S, et al. 1998b. Prediction of pharmacokinetic alterations caused by drug-drug interactions: metabolic interaction in the liver. Pharmacol Rev, 50:387-411.

Jacobsen W, Christians U, Benet LZ. 2000. In vitro evaluation of the disposition of A novel cysteine protease inhibitor. Drug Metab Dispos, 28:1343-51.

Jaeschke H, Gores GJ, Cederbaum AI, et al. 2002. Mechanisms of hepatotoxicity. Toxicol Sci, 65:166-76.

Jenkins IR, Gibson J. 1996. Cisapride, erythromycin and arrhythmia. Anaesth Intensive Care, 24:728.

Jones DR, Gorski JC, Hamman MA, et al. 1999. Diltiazem inhibition of cytochrome P-450 3A activity is due to metabolite intermediate complex formation. J Pharmacol Exp Ther, 290:1116-25.

Ju C, Uetrecht JP. 2002. Mechanism of idiosyncratic drug reactions: reactive metabolite formation, protein binding and the regulation of the immune system. Curr Drug Metab, 3:367-77.

Jurima-Romet M, Crawford K, Cyr T, et al. 1994. Terfenadine metabolism in human liver. In vitro inhibition by macrolide antibiotics and azole antifungals. Drug Metab Dispos, 22:849-57.

Kanamitsu S, Ito K, Green CE, et al. 2000. Prediction of in vivo interaction between triazolam and erythromycin based on in vitro studies using human liver microsomes and recombinant human CYP3A4. Pharm Res, 17:419-26.

Katoh T, Saitoh H, Ohno N, et al. 2003. Drug interaction between mosapride and erythromycin without electrocardiographic changes. Jpn Heart $J, 44: 225-34$.

Kent UM, Aviram M, Rosenblat M, et al. 2002. The licorice root derived isoflavan glabridin inhibits the activities of human cytochrome P450S 3A4, 2B6, and 2C9. Drug Metab Dispos, 30:709-15.

Kent UM, Juschyshyn MI, Hollenberg PF. 2001. Mechanism-based inactivators as probes of cytochrome $\mathrm{P} 450$ structure and function. Curr Drug Metab, 2:215-43.

Khan KK, He YQ, Domanski TL, et al. 2002. Midazolam oxidation by cytochrome P450 3A4 and active-site mutants: an evaluation of multiple binding sites and of the metabolic pathway that leads to enzyme inactivation. Mol Pharmacol, 61:495-506.

Kharasch ED, Hoffer C, Walker A, et al. 2003. Disposition and miotic effects of oral alfentanil: a potential noninvasive probe for first-pass cytochrome P4503A activity. Clin Pharmacol Ther, 73:199-208.

Klausner MA. 1999. Astemizole use with erythromycin. Ann Allergy Asthma Immunol, 83:422.

Komatsu T, Yamazaki H, Asahi S, et al. 2000. Formation of a dihydroxy metabolite of phenytoin in human liver microsomes/cytosol: roles of cytochromes P4502C9, 2C19, and 3A4. Drug Metab Dispos, 28: $1361-8$.

Koudriakova T, Iatsimirskaia E, Utkin I, et al. 1998. Metabolism of the human immunodeficiency virus protease inhibitors indinavir and ritonavir by human intestinal microsomes and expressed cytochrome P4503A4/3A5: mechanism-based inactivation of cytochrome P4503A by ritonavir. Drug Metab Dispos, 26:552-61.

Krahenbuhl S, Menafoglio A, Giostra E, et al. 1998. Serious interaction between mibefradil and tacrolimus. Transplantation, 66:1113-15.

Kurowski M, Kaeser B, Sawyer A, et al. 2002. Low-dose ritonavir moderately enhances nelfinavir exposure. Clin Pharmacol Ther, $72: 123-32$.

Kutt H, Verebely K, McDowell F. 1968. Inhibition of diphenylhydantoin metabolism in rats and in rat liver microsomes by antitubercular drugs. Neurology, 18:706-10.

Kyrmizakis DE, Chimona TS, Kanoupakis EM, et al. 2002. QT prolongation and torsades de pointes associated with concurrent use of cisapride and erythromycin. Am J Otolaryngol, 23:303-7.

Laganière S, Davies RF, Carignan G, et al. 1996. Pharmacokinetic and pharmacodynamic interactions between diltiazem and quinidine. Clin Pharmacol Ther, 60:255-64. 
Lightning LK, Jones JP, Friedberg T, et al. 2000. Mechanism-based inactivation of cytochrome P450 3A4 by L-754,394. Biochemistry, 39:4276-87.

Lillibridge JH, Liang BH, Kerr BM, et al. 1998. Characterization of the selectivity and mechanism of human cytochrome P450 inhibition by the human immunodeficiency virus-protease inhibitor nelfinavir mesylate. Drug Metab Dispos, 26:609-16.

Lin HL, Kent UM, Hollenberg PF. 2002. Mechanism-based inactivation of cytochrome P450 3A4 by 17 alpha-ethynylestradiol: evidence for heme destruction and covalent binding to protein. J Pharmacol Exp Ther, 301:160-7.

Lin JH, Lu AYH. 1998. Inhibition and induction of cytochrome P450 and the clinical implications. Clin Pharmacokinet, 35:361-90.

Lodwick R, McConkey B, Brown AM. 1987. Life threatening interaction between tamoxifen and warfarin. BMJ, 295:1141.

Luo G, Lin J, Fiske WD, et al. 2003. Concurrent induction and mechanismbased inactivation of CYP3A4 by an L-valinamide derivative. Drug Metab Dispos, 31:1170-5.

Ma B, Prueksaritanont T, Lin JH. 2000. Drug interactions with calcium channel blockers: possible involvement of metabolite-intermediate complexation with CYP3A. Drug Metab Dispos, 28:125-30.

Masubuchi Y, Horie T. 1999. Mechanism-based inactivation of cytochrome $\mathrm{P} 450 \mathrm{~s} 1 \mathrm{~A} 2$ and $3 \mathrm{~A} 4$ by dihydralazine in human liver microsomes. Chem Res Toxicol, 12:1028-32.

Masubuchi Y, Ose A, Horie T. 2002. Diclofenac-induced inactivation of CYP3A4 and its stimulation by quinidine. Drug Metab Dispos, 30:1143-8.

Mayhew BS, Jones DR, Hall SD. 2000. An in vitro model for predicting in vivo inhibition of cytochrome P450 3A4 by metabolic intermediate complex formation. Drug Metab Dispos, 28:1031-7.

Meibohm B, Beierle I, Derendorf H. 2002. How important are gender differences in pharmacokinetics? Clin Pharmacokinet, 41:329-42.

Michalets EL, Williams CR. 2000. Drug interactions with cisapride: clinical implications. Clin Pharmacokinet, 39:49-75.

Miller RR, Porter J, Greenblatt DJ. 1979. Clinical importance of the interaction of phenytoin and isoniazid: a report from the Boston Collaborative Drug Surveillance Program. Chest, 75:356-8.

Miura T, Iwasaki M, Komori M, et al. 1989. Decrease in a constitutive form of cytochrome P-450 by macrolide antibiotics. J Antimicrob Chemother, 24:551-9.

Mota CR, Carvalho C, Mota C, et al. 1996. Severe carbamazepine toxicity induced by concurrent erythromycin therapy. Eur J Pediatr, 155:345.

Muck W. 2000. Metabolic interactions between mibefradil and HMG-CoA reductase inhibitors: linking in vitro with in vivo information. $\mathrm{Br} \mathrm{J}$ Clin Pharmacol, 49:87-90.

Mullins ME, Horowitz Z, Linden DHJ, et al. 1998. Life-threatening interaction of mibefradil and beta-blockers with dihydropyridine calcium channel blockers. JAMA, 280:157-8.

Naisbitt DJ, Pirmohamed M, Park BK. 2003. Immunopharmacology of hypersensitivity reactions to drugs. Curr Allergy Asthma Rep, 3: 222-9.

Naisbitt DJ, Williams DP, Pirmohamed M, et al. 2001. Reactive metabolites and their role in drug reactions. Curr Opin Allergy Clin Immunol, $1: 317-25$

Nelson DR, Koymans L, Kamataki T, et al. 1996. P450 superfamily: update on new sequences, gene mapping, accession numbers and nomenclature. Pharmacogenetics, 6:1-42.

Nolan CM, Sandblom RE, Thummel KE, et al. 1994. Hepatotoxicity associated with acetaminophen usage in patients receiving multiple drug therapy for tuberculosis. Chest, 105:408-11.

Ortiz de Montellano PR, Correia MA. 1995. Inhibition of cytochrome P450. In Ortiz de Montellano PR (ed). Cytochrome P450: structure, mechanism and biochemistry. New York: Plenum Pr. p 305-66.

Osawa Y, Pohl LR. 1989. Covalent bonding of the prosthetic heme to protein: a potential mechanism for suicide inactivation or activation of hemoproteins. Chem Res Toxicol, 2:131-41.
Ouellet D, Hsu A, Granneman GR, et al. 1998. Pharmacokinetic interaction between ritonavir and clarithromycin. Clin Pharmacol Ther, 64: $355-62$.

Patsalos PN, Froscher W, Pisani F, et al. 2002. The importance of drug interactions in epilepsy therapy. Epilepsia, 43:365-85.

Pessayre D, Tinel M, Larrey D, et al. 1983. Inactivation of cytochrome P450 by a troleandomycin metabolite. Protective role of glutathione. $J$ Pharmacol Exp Ther, 224:685-91.

Pirmohamed M, Naisbitt DJ, Gordon F, et al. 2002. The danger hypothesispotential role in idiosyncratic drug reactions. Toxicology, 181-182: $55-63$.

Piscitelli SC, Formentini E, Burstein AH, et al. 2002. Effect of milk thistle on the pharmacokinetics of indinavir in healthy volunteers. Pharmacotherapy, 22:551-6.

Prueksaritanont T, Ma B, Tang C, et al. 1999. Metabolic interactions between mibefradil and HMG-CoA reductase inhibitors: an in vitro investigation with human liver preparations. $\mathrm{Br} J$ Clin Pharmacol, 47:291-8.

Pumford NR, Halmes NC. 1997. Protein targets of xenobiotic reactive intermediates. Annu Rev Pharmacol Toxicol, 37:91-117.

Ragosta M, Weihl AC, Rosenfeld LE. 1989. Potentially fatal interaction between erythromycin and disopyramide. Am J Med, 86:465-6.

Rendic S. 2002. Summary of information on human CYP enzymes: human P450 metabolism data. Drug Metab Rev, 34:83-448.

Rendic S, Di Carlo FJ. 1997. Human cytochrome P450 enzyme: a status report summarizing their reactions, substrates, induction, and inhibitors. Drug Metab Rev, 29:413-580.

Ritchie LD, Grant SM. 1989. Tamoxifen-warfarin interaction: the Aberdeen hospitals drug file. $B M J, 298: 1253$.

Rubinstein E. 2001. Comparative safety of the different macrolides. Int $J$ Antimicrob Agents, 18:S71-6.

Sadler BM, Piliero PJ, Preston SL, et al. 2001. Pharmacokinetics and safety of amprenavir and ritonavir following multiple-dose, co-administration to healthy volunteers. AIDS, 15:1009-18.

Sadrieh N, Thomas PE. 1994. Characterization of rat cytochrome P450 isozymes involved in the covalent binding of cyclosporin A to microsomal proteins. Toxicol Appl Pharmacol, 127:222-32.

Schmassmann-Suhijar D, Bullingham R, Gasser R, et al. 1998. Rhabdomyolysis due to interaction of simvastatin with mibefradil. Lancet, 351:1929-30.

Schmiedlin-Ren P, Edwards DJ, Fitzsimmons ME, et al. 1997. Mechanisms of enhanced oral availability of CYP3A4 substrates by grapefruit constituents. Decreased enterocyte CYP3A4 concentration and mechanism-based inactivation by furanocoumarins. Drug Metab Dispos, 25:1228-33.

Schmucker DL. 2001. Liver function and phase I drug metabolism in the elderly: a paradox. Drug Aging, 18:837-51.

Schrag ML, Wienkers LC. 2001. Covalent alteration of the CYP3A4 active site: evidence for multiple substrate binding domains. Arch Biochem Biophys, 391:49-55.

Self TH, Chrisman CR, Baciewicz AM, et al. 1999. Isoniazid drug and food interactions. Am J Med Sci, 317:304-11.

Sham HL, Kempf DJ, Molla A, et al. 1998. ABT-378, a highly potent inhibitor of the human immunodeficiency virus protease. Antimicrob Agents Chemother, 42:3218-24.

Shimada T, Yamazaki H, Mimura M, et al. 1994. Interindividual variations in human liver cytochrome P450 enzymes involved in the oxidation of drugs, carcinogens and toxic chemicals. J Pharmacol Exp Ther, 270:414-23.

Siepmann M, Kleinbloesem C, Kirch W. 1995. The interaction of the calcium antagonist RO 40-5967 with digoxin. Br J Clin Pharmacol, 39:491-6.

Silverman RB. 1988. Mechanism-based enzyme inactivation: chemistry and enzymology. Boca Raton: CRC Pr.

Silverman RB. 1998. Mechanism-based enzyme inactivation: chemistry and enzymology. Boca Raton: CRC Pr. 
Simonsen U. 2002. Interactions between drugs for erectile dysfunction and drugs for cardiovascular disease. Int J Impot Res, 14:178-88.

Spina E, Pisani F, Perucca E. 1996. Clinically significant pharmacokinetic drug interactions with carbamazepine. An update. Clin Pharmacokinet, $31: 198-214$.

Spinler SA, Cheng JW, Kindwall KE, et al. 1995. Possible inhibition of hepatic metabolism of quinidine by erythromycin. Clin Pharmacol Ther, 57:89-94.

Spoendlin M, Peters J, Welker H, et al. 1998. Pharmacokinetic interaction between oral cyclosporin and mibefradil in stabilized post-renaltransplant patients. Nephrol Dial Transplant, 13:1787-91.

Sridar C, Goosen TC, Kent UM, et al. 2004. Silybin inactivates cytochromes P450 3A4 and 2C9 and inhibits major hepatic glucuronosyltransferases. Drug Metab Dispos, 32:587-94.

Stupans I, Murray M, Kirlich A, et al. 2001. Inactivation of cytochrome P450 by the food-derived complex phenol oleuropein. Food Chem Toxicol, 39:1119-24.

Tagawa T, Mimaki T, Ono J, et al. 1989. Erythromycin-induced carbamazepine intoxication in two epileptic children. Jpn J Psychiatry Neurol, 43:513-14.

Tenni P, Lalich DL, Byrne MJ. 1989. Life threatening interaction between tamoxifen and warfarin. $B M J, 298: 93$.

Thummel KE, Shen DD, Podoll TD, et al. 1994. Use of midazolam as a human cytochrome $\mathrm{P} 4503 \mathrm{~A}$ probe: I. In vitro-in vivo correlations in liver transplant patients. J Pharmacol Exp Ther, 271:549-56.

Tinel M, Descatoire V, Larrey D, et al. 1989. Effects of clarithromycin on cytochrome P-450. Comparison with other macrolides. J Pharmacol Exp Ther, 250:746-51.

Tornqvist M, Fred C, Haglund J, et al. 2002. Protein adducts: quantitative and qualitative aspects of their formation, analysis and applications. J Chromatogr B Analyt Technol Biomed Life Sci, 778:279-308.

Toyosaki N, Toyo-Oka T, Natsume T, et al. 1988. Combination therapy with diltiazem and nifedipine in patients with effort angina pectoris. Circulation, 77:1370-5.

Tsao S-C, Dickinson TH, Abernethy DR. 1990. Metabolite inhibition of parent drug biotransformation. Studies of diltiazem. Drug Metab Dispos, 18:180-2.

Tsutsumi K, Kotegawa T, Kuranari M, et al. 2002. The effect of erythromycin and clarithromycin on the pharmacokinetics of intravenous digoxin in healthy volunteers. J Clin Pharmacol, 42: 1159-64.

Turner PV, Renton KW. 1989. The interaction between carbamazepine and erythromycin. Can J Physiol Pharmacol, 67:582-6.

Varis T, Backman JT, Kivisto KT, et al. 2000. Diltiazem and mibefradil increase the plasma concentrations and greatly enhance the adrenalsuppressant effect of oral methylprednisolone. Clin Pharmacol Ther, 67:215-21.

Vereerstraeten P, Thiry P, Kinnaert P, et al. 1987. Influence of erythromycin on cyclosporine pharmacokinetics. Transplantation, 44:155-6.

von Moltke LL, Durol AL, Duan SX, et al. 2000. Potent mechanism-based inhibition of human CYP3A in vitro by amprenavir and ritonavir: comparison with ketoconazole. Eur J Clin Pharmacol, 56:259-61. von Richter O, Burk O, Fromm MF, et al. 2004. Cytochrome P450 3A4 and P-glycoprotein expression in human small intestinal enterocytes and hepatocytes: a comparative analysis in paired tissue specimens. Clin Pharmacol Ther, 75:172-83.

Voorman RL, Maio SM, Hauer MJ, et al. 1998. Metabolism of delavirdine, a human immunodeficiency virus type-1 reverse transcriptase inhibitor, by microsomal cytochrome $\mathrm{P} 450$ in humans, rats, and other species: probable involvement of CYP2D6 and CYP3A. Drug Metab Dispos, 26:631-9.

Watanabe M, Kumai T, Matsumoto N, et al. 2004. Expression of CYP3A4 mRNA is correlated with CYP3A4 protein level and metabolic activity in human liver. $J$ Pharmacol Sci, 94:459-62.

Watkins PB. 1994. Noninvasive tests of CYP3A enzymes. Pharmacogenetics, 4:171-84.

Watkins PB, Murray SA, Winkelman LG, et al. 1989. Erythromycin breath test as an assay of glucocorticoid-inducible liver cytochromes P-450. Studies in rats and patients. J Clin Invest, 83:688-97.

Weibert RT, Lorentz SM, Townsend RJ, et al. 1989. Effect of erythromycin in patients receiving long-term warfarin therapy. Clin Pharm, 8: 210-14.

Welker HA, Wiltshire H, Bullingham R. 1998. Clinical pharmacokinetics of mibefradil. Clin Pharmacokinet, 35:405-23.

Wen X, Wang JS, Neuvonen PJ, et al. 2002. Isoniazid is a mechanismbased inhibitor of cytochrome P450 1A2, 2A6, 2C19 and 3A4 isoforms in human liver microsomes. Eur J Clin Pharmacol, 57:799-804.

Williams D, Feely J. 2002. Pharmacokinetic-pharmacodynamic drug interactions with HMG-CoA reductase inhibitors. Clin Pharmacokinet, 41:343-70.

Yamano K, Yamamoto K, Katashima M, et al. 2001. Prediction of midazolam-CYP3A inhibitors interaction in the human liver from in vivo/in vitro absorption, distribution, and metabolism data. Drug Metab Dispos, 29:443-52.

Yasui N, Otani K, Kaneko S, et al. 1996. A kinetic and dynamic study of oral alprazolam with and without erythromycin in humans: in vivo evidence for the involvement of CYP3A4 in alprazolam metabolism. Clin Pharmacol Ther, 59:514-19.

Yeates RA, Laufen H, Zimmermann T, et al. 1997. Pharmacokinetic and pharmacodynamic interaction study between midazolam and the macrolide antibiotics, erythromycin, clarithromycin, and the azalide azithromycin. Int $J$ Clin Pharmacol Ther, 35:577-9.

Yeo KR, Yeo WW. 2001. Inhibitory effects of verapamil and diltiazem on simvastatin metabolism in human liver microsomes. Br J Clin Pharmacol, 51:461-70.

Zdravkovic M, Olsen AK, Christiansen T, et al. 2003. A clinical study investigating the pharmacokinetic interaction between NN703 (tabimorelin), a potential inhibitor of CYP3A4 activity, and midazolam, a CYP3A4 substrate. Eur J Clin Pharmacol, 58:683-8.

Zhao XJ, Jones DR, Wang YH, et al. 2002. Reversible and irreversible inhibition of CYP3A enzymes by tamoxifen and metabolites. Xenobiotica, 32:863-78.

Zitelli BJ, Howrie DL, Altman H, et al. 1987. Erythromycin-induced drug interactions. An illustrative case and review of the literature. Clin Pediatr (Phila), 26:117-19. 
